\begin{tabular}{|l|l|l|l|l|l|}
\hline J. Tek. Ling & Vol. 12 & No. 1 & Hal. $67-74$ & Jakarta, Januari 2011 & ISSN 1441-318X \\
\hline
\end{tabular}

\title{
EMISI GAS BUANG KENDARAAN BERMOTOR BERBAHAN BAKAR GAS CAIR (LGV) DAN PERTAMAX PADA KONDISI UJI AWAL DINGIN DAN PANAS
}

\author{
Prawoto \\ Peneliti di Balai Termodinamika, Motor dan Propulsi \\ (BTMP) - BPPT
}

\begin{abstract}
Liquid Gas Vehicle (LGV) is one of an alternative hydrocarbon fuel, which is the dominant composition are propane and butane, and now is already available in the market. With low sulfur content and high octane number, theoritically vehicle emissions using LGV are better than gasoline. But it is need a good mixture ratio of air to LGV (AFR) in the gas mixer before enter to the engine. This paper describes a study that compared emission test results from gasoline engine using LGV with standard mixer and Pertamax market fuel. The study was based on the vehicle chassis dynamometer test results according to the UN-ECE R83-04 test cycle standard on both cold and hot starts. The test results have shown that on urban cycle $\mathrm{CO}$ and $\mathrm{HC}$ emissions of Pertamax fuel was better than $L G V$ on both cold and hot starts. Whereis on extra urban cycle CO emission of LGV fuel was better than Pertamax. NOx emission of LGV fuel was very low and practically undetected for all test condition. Utilisation of LGV fuel reduce $\mathrm{CO} 2$ emission in order of $15 \%$ for urban drive cycle for both cold and hot start, and in order of $9,2 \%$ for cold start and $10.5 \%$ for hot start for mixed cycle.
\end{abstract}

Key words: LGV, exhaust gas emission, cold start, hot start.

\section{PENDAHULUAN}

Seiring dengan terus naiknya harga bahan bakar minyak membuat penggunaan sumber energi lain yang dapat menggantikan gasoline akan menjadi alternatif yang menarik. Diantara bahan bakar alternatif tersebut adalah bahan bakar gas, yang salah satunya adalah produksi terbaru pertamina yang diberi nama liquid gas for vehicle (LGV). LGV menarik karena meskipun tidak tersedia dalam jumlah yang besar seperti Compressor National Gas (CNG), namun masih lebih murah harganya dibanding gasoline dan mempunyai tekanan penyimpanan yang lebih rendah dibanding CNG, sehingga dari factor keamanan LGV lebih unggul dibanding CNG. Berbeda dengan CNG yang lebih ringan dan mudah tercampur dengan udara, maka untuk mendapatkan pencampuran yang baik antara LGV dan udara dalam rangka menaikkan efisiensi pembakaran diperlukan proses pencampuran yang baik di dalam mixer. Penggunaan mixer yang biasa digunakan untuk bahan bakar CNG memerlukan beberapa modifikasi untuk dapat digunakan dengan bahan bakar LGV sehingga tercapai kenaikan efisiensi 
pembakaran dan penurunan emisi gas buang.

Sampai saat ini regulasi emisi untuk kendaran berbahan bakar gasoline dan gas adalah $\mathrm{CO}, \mathrm{HC}$ dan $\mathrm{NO}_{\mathrm{x}}$. $\mathrm{CO}$ sebagian besar dihasilkan oleh pembakaran yang tidak sempurna karena kurangnya oksigen dalam ruang bakar. Secara teoritis $\mathrm{CO}$ dan $\mathrm{HC}$ tidak akan terjadi jika oksigennya lebih banyak dibandingkan kebutuhan oksigen pada perbandingan udara-bahan bakar Air Fuel Ratio (AFR) teoritis (stoikiometri) dan campuran miskin. Namun kenyataannya dalam campuran yang miskinpun disamping $\mathrm{CO}_{2}$ dan $\mathrm{H}_{2} \mathrm{O}$ juga tetap dihasilkan $\mathrm{CO}$ dan $\mathrm{HC}$. Hal ini dikarenakan pembakaran tidak pernah terjadi secara sempurna. $\mathrm{CO}$ dapat diubah menjadi $\mathrm{CO}_{2}$ dengan oksidasi, namun karena reaksi ini termasuk jenis reaksi yang sangat lambat, maka tidak dapat merubah semua $\mathrm{CO}$ menjadi $\mathrm{CO}_{2}$. Sehingga $\mathrm{CO}$ tetap terjadi walaupun campurannya sangat miskin ${ }^{1)}$. Dua sumber utama terjadinya CO adalah pembakaran tidak sempurna karena ketidak rataan distribusi campuran udara-bahan bakar dalam ruang bakar, dan temperatur yang rendah disekitar dinding silinder, yang lebih dikenal dengan istilah "quenching". Dengan temperatur yang ada tersebut, maka menjadi terlalu rendah untuk dapat berlangsungnya proses pembakaran, sehingga api tidak dapat mencapai daerah sekitar dinding silinder ${ }^{2}$.

Seperti halnya $\mathrm{CO}$, faktor utama yang mempengaruhi jumlah $\mathrm{HC}$ dalam emisi adalah AFR yang tidak tepat dan "quenching". Sampai titik tertentu, kandungan HC dalam gas buang akan bertambah dengan bertambah kayanya campuran udara-bahan bakar, menyebabkan pembakaran tidak sempurna karena kekurangan oksigen. Jika campuran dibuat menjadi terlalu miskin maka konsentrasi HC tidak menurun tetapi akan kembali bertambah besar. Hal ini dikarenakan kekurangan bahan bakar menyebabkan pembakaran menurun, dan mengakibatkan bahan bakar ikut keluar dari ruang bakar sebelum terbakar semuanya, dan kegagalan pembakaran (misfiring) akan terjadi. Pada sisi lain dekat diding silinder terjadi perpindahan panas yang besar ke dinding silinder sebelum api mencapai diding silinder tersebut, mengakibatkan temperatur lidah api menurun secara drastis didaerah quenching zone atau daerah pemadaman, dan di daerah tersebut proses penyalaan campuran-udara bahan bakar menjadi terhambat. Quenching zone lebih kecil pada AFR yang rendah (campuran kaya), sebaliknya menjadi besar ketika campuran menjadi miskin. Penambahan quenching zone berbanding terbalik dengan tekanan dalam silinder ${ }^{2}$. Jadi sangat jelas bahwa konsentrasi $\mathrm{CO}$ dan $\mathrm{HC}$ dalam gas buang umumnya ditentukan dari AFR, dan secara prinsip bervariasi dengan perubahan AFR. Konsentrasi $\mathrm{CO}$ akan menurun drastis dengan naiknya perbandingan udara-bahan bakar. Cara terbaik untuk menurunkan konsentrasi $\mathrm{CO}$ dan $\mathrm{HC}$ adalah dengan mengusahakan pembakaran sempurna, dengan cara membuat AFR setinggi mungkin yang dapat dilakukan. Namun campuran yang terlalu miskin akan menimbulkan masalah yang lain yaitu rendahnya tingkat pembakaran, dan mengakibatkan naiknya konsentrasi $\mathrm{HC}$ pada gas buang. Campuran terbaik untuk proses pembakaran adalah campuran stoikiometri.

Sembilanpuluh lima persen $(95 \%) \mathrm{NO}_{x}$ ditemukan pada gas buang sebagai NO, yang terbentuk dalam ruang bakar dengan proses berikut :

$$
\mathrm{N}_{2}+\mathrm{O}_{2} \quad 2 \mathrm{NO}
$$

NO kemudian bereaksi dengan $\mathrm{O}_{2}$ di udara menjadi $\mathrm{NO}_{2}$.

$$
2 \mathrm{NO}+\mathrm{O}_{2} \quad 2 \mathrm{NO}_{2}
$$

$\mathrm{N}_{2}$ yang merupakan komposisi terbesar di udara $(79 \%)$ adalah gas yang stabil dalam kondisi normal. Tetapi pada temperatur tinggi (di atas $1800^{\circ} \mathrm{C}$ ) dengan konsentrasi oksigen yang tinggi akan sangat mudah terbentuk NO 
sesuai reaksi (1) di atas. Jadi pada umumnya NOx terbentuk selama proses pembakaran sempurna, berbeda dengan apa yang terjadi pada proses pembentukan $\mathrm{CO}$ dan $\mathrm{HC}$. Karena pada proses pembakaran sempurna temperatur cukup tinggi untuk membantu proses terjadinya NO. Faktor-faktor utama yang mempengaruhi konsentrasi $\mathrm{NO}_{\mathrm{x}}$ selama pembakaran diantaranya, maksimum temperatur yang dapat dicapai dalam ruang bakar, dan perbandingan udara bahan-bakar (AFR). Sehingga jalan terbaik untuk mengurangi kandungan $\mathrm{NO}_{\mathrm{x}}$ dalam gas buang yaitu dengan mengupayakan temperatur dalam ruang bakar tidak melebihi $1800^{\circ} \mathrm{C}$, atau dengan mengusahakan sesingkat mungkin pencapaian temperatur maksimum. Cara lain adalah dengan mengurangi konsentrasi $\mathrm{O}_{2}$.

Dari uraian di atas sangat jelas bahwa faktor AFR sangat dominan dalam proses pembakaran. Oleh karena itu diperlukan optimasi pencampuran udara-bahan bakar LGV yang sangat baik di dalam mixer untuk mendapatkan AFR didaerah stoikiometri, sehingga menghasilkan unjuk kerja terbaik dan tingkat emisi gas buang terendah. Optimasi konfigurasi mixer telah dilakukan dengan menggunakan perengkat lunak fluent dengan dasar geometri mixer yang ada di pasar untuk kendaraan di bawah $3000 \mathrm{cc}^{3)}$.

\section{METODE PENELITIAN}

\subsection{Alat dan Metode Uji Emisi Gas Buang}

Alat uji meliputi kendaraan, bangku uji (chassis dynamometer/CD) dan sistem pengambilan sampel serta analisis gas buang. Dalam pengujian ini digunakan kendaran Ford Escape 3.0 liter tahun 2004 dengan dua jenis bahan bakar berbeda, yaitu: LGV dan pertamax. Kendaraan yang digunakan telah memenuhi standar ambang batas emisi Euro 2 sesuai peraturan meteri lingkungan hidup No. 04/2009.
Alat uji dan alat ukur utama yang dipergunakan adalah sebagai berikut:

- Dinamometer dengan Single Roll Chassis Dynamometer 48 inch diameter.

- Sistem pengukuran aliran dengan Constant Volume Sampling (CVS) Critical Flow Ventury.

- Non-Dispersive Infra Red Analyzer (NDIR) untuk analisa gas $\mathrm{CO} \& \mathrm{CO}_{2}$.

- Chemiluminescent Analyzer untuk analisa gas $\mathrm{NO}_{x}$.

- Flame Ionization Detector Analyzer (FID) untuk analisa gas $\mathrm{HC}$, dan

- Paramagnetic Analyzer untuk analisa gas $\mathrm{O}_{2}$

- Sistem akuisisi data dilakukan secara otomatis dengan program Autotest.

Pengujian dilakukan dengan mengacu pada standar ECE R83-04, pada kondisi awal uji dingin (cold stard) maupun kondisi awal uji panas (hot start). Cold start berarti pengukuran emisi langsung dilakukan saat mobil di nyalakan, sedangkan hot start pengukuran emisi baru dilakukan setelah mobil dinyalakan selama 40 detik. Kendaraan dikondisikan sesuai prosedur yang ditentukan ${ }^{4}$. Contoh pengujian kendaraan ditunjukkan dalam Gambar 1 dan secara skematis siklus pengujian emisi dengan metode UN-ECE R 83-04 ditunjukkan dalam Gambar 2. Pengukuran emisi dilakukan pada siklus uji urban drive cycle, yang mensimulasikan kondisi perkotaan, extra urban drive cycle, yang mensimulasikan kondisi jalan bebas hambatan dan siklus uji campuran keduanya (mixed cycle).

Pengujian meliputi semua aspek emisi gas buang yang terdiri atas $\mathrm{CO}, \mathrm{HC}, \mathrm{NO}_{\mathrm{x}}$ dan $\mathrm{CO}_{2}$. Pengujian pada kondisi awal dingin (cold start) dan kondisi awal panas (hot start) terutama untuk mengetahui pengaruh saat penyalaan (start) terhadap emisi gas buang. Metode pengukuran emisi gas buang diberikan dalam Tabel1. 
Tabel 1. Metode pengukuran emisi gas buang

\begin{tabular}{|l|l|l|}
\hline Jenis Emisi Gas Buang & Metode Uji & Metode Ukur \\
\hline CO & UN ECE R83-04 & NDIR \\
\hline HC & UN ECE R83-04 & FID \\
\hline NOX & UN ECE R83-04 & Chemiluminescent \\
\hline CO2 & UN ECE R83-04 & NDIR \\
\hline
\end{tabular}

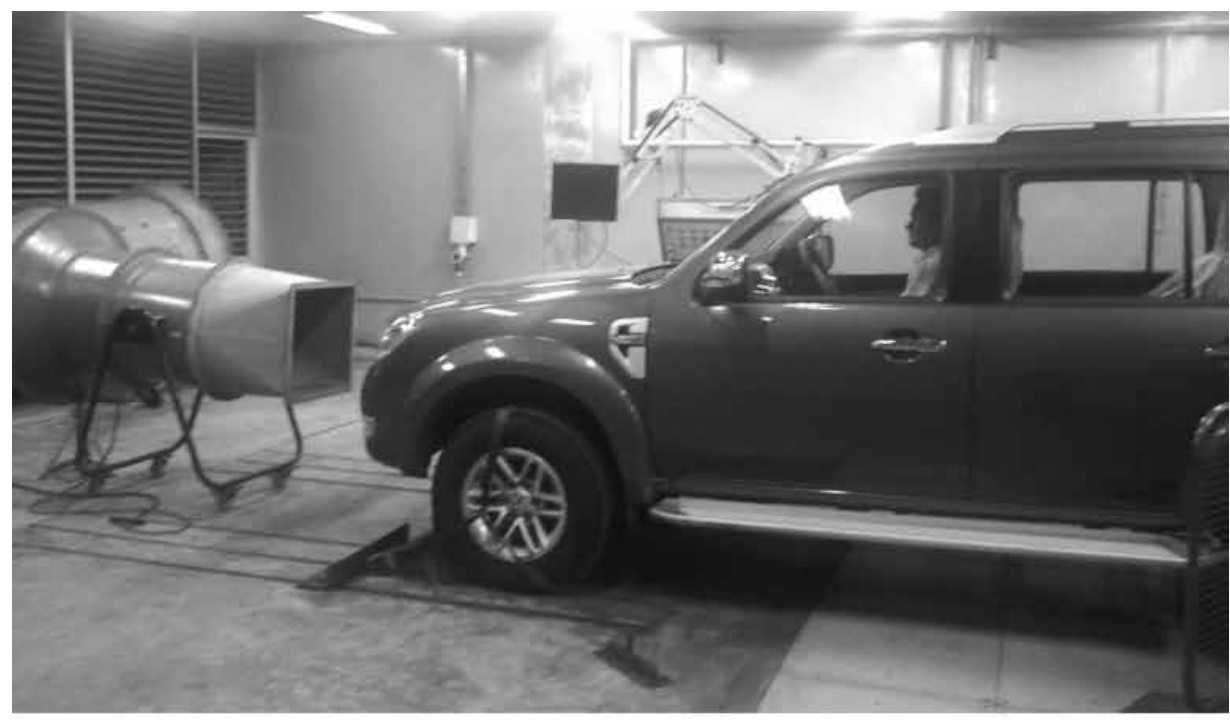

Gambar 1. Pengujian kendaraan dengan chasis dynamometer.

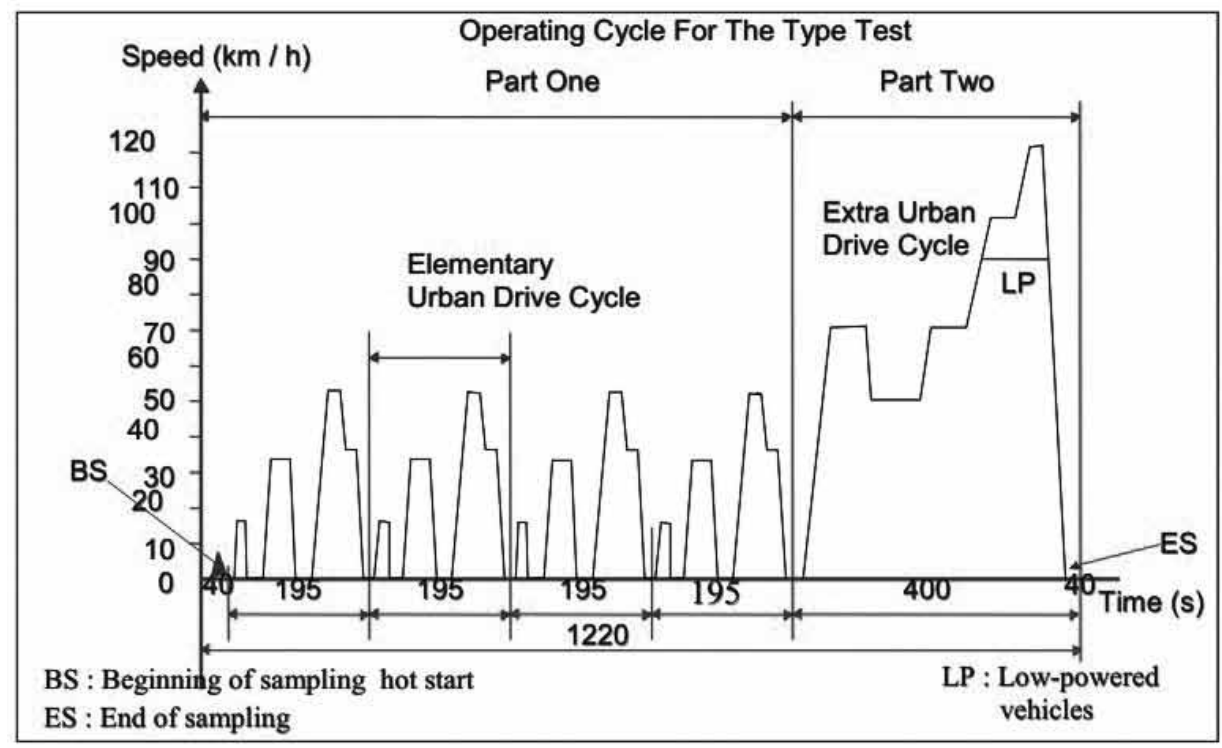

Gambar 2. Siklus uji emisi gas buang kendaraan bermotor roda 4 (ECE R83-04)4). 


\section{HASIL DAN PEMBAHASAN}

Hasil uji emisi gas buang yang meliputi $\mathrm{CO}, \mathrm{HC}, \mathrm{NO}_{\mathrm{x}}$ dan $\mathrm{CO}_{2}$ pada kondisi awal uji dingin (cold start) dan kondisi awal uji panas (hot start) masing-masing diberikan pada Tabel 2 dan Tabel 3. dan secara grafik diberikan dalam Gambar 3. Dari hasil uji tersebut terlihat bahwa baik untuk kondisi awal uji dingin (Tabel 2) maupun kondisi awal uji panas (Tabel 3) kecuali pada siklus uji bebas hambatan (urban cycle) emisi CO dengan bahan bakar pertamax lebih baik dibanding LGV. Sedangkan untuk siklus bebas hambatan (extra urban cycle) kondisi sebaliknya terjadi, dimana emisi CO dengan bahan bakar LGV hanya sepertiga emisi CO dari pertamax. Sehingga secara total untuk siklus gabungan penggunaan LGV akan meningkatkan emisi CO sebesar $450 \%$ dibandingkan emisi CO bahan bakar Pertamax untuk start dingin dan sebesar $122 \%$ untuk start panas. Walaupun terjadi peningkatan yang cukup besar namun masih berada di bawah ambang batas yang ditentukan $(84 \%$ lebih rendah untuk start dingin dan $95 \%$ lebih rendah untuk start panas). Kondisi start sangat berpengaruh terhadap emisi $\mathrm{CO}$ terutama pada siklus urban. Hal ini terjadi karena pada kondisi awal start terutama start dingin dimana emisi gas buang langsung diukur bersamaan dengan saat penyalaan, proses pencampuran belum terjadi dengan baik dan campuran antara udara-bahan bakar dalam kondisi yang terlalu kaya, sehingga menghasilkan pembakaran yang tidak sempurna. Sebagaimana kita ketahui pada proses pembakaran tidak sempurna hasil utama adalah emisi CO. Indikasi campuran udara-bahan bakar yang terlalu kaya untuk LGV juga terlihat dari hasil uji emisi HC dan $\mathrm{NO}_{x}$, dimana terjadi peningkatan $\mathrm{HC}$ ratarata untuk urban cycle, extra urban cycle dan mixed cycle masig-masing sebesar
$40 \%, 66 \%$ dan $37,5 \%$ pada start dingin (Tabel 2), dan $63 \%, 150 \%$ serta $100 \%$ pada start panas (Tabel2). Sedangkan untuk emisi $\mathrm{NO}_{\mathrm{x}}$ dari bahan bakar LGV praktis tidak terdeteksi untuk kondisi campuran yang diuji, hal ini mengindikasikan rendahnya temperatur pembakaran yang ada. $\mathrm{NO}_{x}$ merupakan hasil disosiasi antara $\mathrm{N}_{2}$ dan $\mathrm{O}_{2}$ pada temperatur pembakaran di atas 1800 ${ }^{\circ} \mathrm{C}$ yang terjadi pada campuran udara-bahan bakar stoikiometri atau pada campuran miskin.

Dengan rendahnya emisi $\mathrm{NO}_{x}$ yang praktis bernilai nol mengindikasikan rendahnya temperatur pembakaran yang umum ditemui pada campuran-campuran yang terlalu kaya ${ }^{2,5)}$. Total emisi regulasi $\mathrm{HC}+\mathrm{NO}_{\mathrm{x}}$ untuk bahan bakar LGV pada siklus campuran terjadi penurunan sebesar $52 \%$ untuk start dingin dan $68 \%$ untuk start panas dibandingkan dengan emisi yang sama dari bahan bakar Pertamax. Hal lain yang menarik dengan penggunaan LGV adalah terjadinya penurunan emisi $\mathrm{CO}_{2}$ untuk semua siklus dan kondisi start terutama untuk siklus urban atau perkotaan. Pada siklus urban baik kondisi start dingin maupun start panas terjadi penurunan $\mathrm{CO}_{2}$ sebesar $15 \%$. Secara rata-rata pada siklus campuran penggunaan LGV dibandingkan Pertamax akan menurunkan $\mathrm{CO}_{2}$ sebesar $9,2 \%$ pada start dingin dan sebesar $10,2 \%$ pada start panas.

Penurunan ini dapat diperbesar dengan optimasi proses pencampuran LGV-udara di dalam mixer, sehingga didapat campuran udara-bahan bakar yang sesuai dan mendekati campuran stoikiometri. Sebagai perbandingan penggunaan CNG dengan sistem yang telah mapan seperti di Jepang memberikan kontribusi penurunan $\mathrm{CO} 2$ sebesar 20\%7). Dari hasil di atas terlihat bahwa penggunaan LGV dapat memberikan kontribusi dalam mengurangi gas rumah kaca dari kendaraan bermotor. 
Tabel 2. Hasil uji emisi gas buang pada kondisi awal dingin (cold start)

\begin{tabular}{|c|c|c|c|c|c|c|c|}
\hline \multirow{3}{*}{ PARAMETER } & \multicolumn{6}{|c|}{ COLD START } & \multirow{3}{*}{$\begin{array}{c}\text { Nilai } \\
\text { Ambang } \\
\text { Batas } \\
\text { (PerMen } \\
\text { LH } \\
\text { 04/2009) }\end{array}$} \\
\hline & \multicolumn{2}{|c|}{ Urban Cycle } & \multicolumn{2}{|c|}{ Extra Urban Cycle } & \multicolumn{2}{|c|}{ Mixed Cycle } & \\
\hline & LGV & Pertamax & LGV & Pertamax & LGV & Pertamax & \\
\hline $\mathrm{CO}[\mathrm{g} / \mathrm{km}]$ & 0.889 & 0.073 & 0.017 & 0.052 & 0.340 & 0.060 & 2.2 \\
\hline $\mathrm{HC}[\mathrm{g} / \mathrm{km}]$ & 0.021 & 0.015 & 0.005 & 0.003 & 0.011 & 0.008 & \\
\hline $\mathrm{N} 0 x[\mathrm{~g} / \mathrm{km}]$ & 0.000 & 0.024 & 0.000 & 0.011 & 0.000 & 0.016 & \\
\hline $\mathrm{HC}+\mathrm{N} 0 \times[\mathrm{g} / \mathrm{km}]$ & 0.021 & 0.039 & 0.005 & 0.014 & 0.011 & 0.023 & 0.5 \\
\hline $\mathrm{CO}_{2}[\mathrm{~g} / \mathrm{km}]$ & 248.341 & 286.522 & 168.967 & 177.461 & 198.378 & 217.823 & \\
\hline $\mathrm{CO}_{2}[\mathrm{~kg} / \mathrm{km}]$ & 0.248 & 0.287 & 0.169 & 0.177 & 0.198 & 0.218 & \\
\hline Faktor Dilusi (DF 1) & 23.864 & 24.058 & 11.062 & 12.019 & & & \\
\hline $\begin{array}{l}\text { Fuel Consumption } \\
\text { [1/100km] }\end{array}$ & 15.363 & 12.101 & 10.394 & 7.495 & 12.235 & 9.199 & \\
\hline Fuel Economy $[\mathrm{km} / \mathrm{l}]$ & 6.509 & 8.264 & 9.621 & 13.343 & 8.173 & 10.870 & \\
\hline Jarak Tempuh [km] & 4.024 & 4.011 & 6.836 & 6.827 & 10.860 & 10.838 & \\
\hline$V \operatorname{mix}\left[\mathrm{m}^{3}\right]$ & 118.104 & 118.937 & 60.505 & 60.921 & 178.609 & 179.858 & \\
\hline
\end{tabular}

Tabel 3. Hasil uji emisi gas buang pada kondisi awal panas (hot start)

\begin{tabular}{|c|c|c|c|c|c|c|c|}
\hline \multirow{3}{*}{ PARAMETER } & \multicolumn{6}{|c|}{ HOT START } & \multirow{3}{*}{$\begin{array}{c}\text { Nilai } \\
\text { Ambang } \\
\text { Batas } \\
\text { (PerMen } \\
\text { LH } \\
\text { 04/2009) }\end{array}$} \\
\hline & \multicolumn{2}{|c|}{ Urban Cycle } & \multicolumn{2}{|c|}{ Extra Urban Cycle } & \multicolumn{2}{|c|}{ Mixed Cycle } & \\
\hline & LGV & Pertamax & LGV & Pertamax & LGV & Pertamax & \\
\hline $\mathrm{CO}[\mathrm{g} / \mathrm{km}]$ & 0.310 & 0.049 & 0.021 & 0.062 & 0.127 & 0.057 & 2.2 \\
\hline $\mathrm{HC}[\mathrm{g} / \mathrm{km}]$ & 0.018 & 0.011 & 0.005 & 0.002 & 0.010 & 0.005 & \\
\hline $\mathrm{N} 0 \mathrm{x}[\mathrm{g} / \mathrm{km}]$ & 0.001 & 0.057 & 0.000 & 0.009 & 0.000 & 0.027 & \\
\hline $\mathrm{HC}+\mathrm{N} 0 x[\mathrm{~g} / \mathrm{km}]$ & 0.018 & 0.069 & 0.005 & 0.011 & 0.010 & 0.032 & 0.5 \\
\hline $\mathrm{CO}_{2}[\mathrm{~g} / \mathrm{km}]$ & 242.795 & 279.937 & 162.736 & 175.998 & 192.279 & 214.178 & \\
\hline $\mathrm{CO}_{2}[\mathrm{~kg} / \mathrm{km}]$ & 0.243 & 0.280 & 0.163 & 0.176 & 0.192 & 0.214 & \\
\hline Faktor Dilusi (DF 1) & 24.707 & 24.336 & 11.511 & 11.913 & & & \\
\hline $\begin{array}{l}\text { Fuel Consumption } \\
{[1 / 100 \mathrm{~km}]}\end{array}$ & 14.965 & 11.821 & 10.011 & 7.433 & 11.839 & 9.045 & \\
\hline Fuel Economy $[\mathrm{km} / \mathrm{l}]$ & 6.682 & 8.459 & 9.989 & 13.453 & 8.446 & 11.056 & \\
\hline Jarak Tempuh [km] & 4.002 & 3.987 & 6.843 & 6.867 & 10.845 & 10.854 & \\
\hline $\operatorname{Vmix}\left[\mathrm{m}^{3}\right]$ & 118.222 & 118.083 & 60.567 & 60.490 & 178.789 & 178.572 & \\
\hline
\end{tabular}




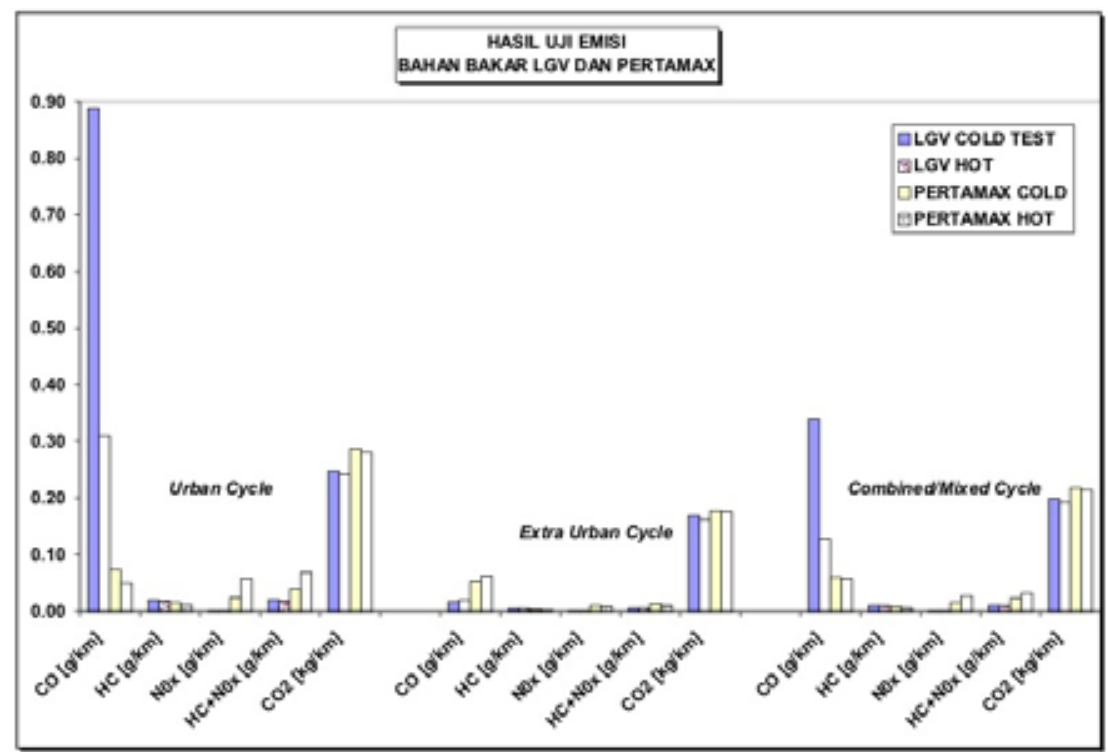

Gambar 3. Grafik emisi gas buang CO, HC, NOx dan CO2 bahan bakar LGV dan pertamax untuk berbagai kondisi uji.

\section{KESIMPULAN}

Dari uraian di atas dapat ditarik beberapa kesimpulan:

a. Dengan menggunakan siklus UNECE R-83 yang merupakan siklus yang diadopsi dalam Peraturan Menteri Lingkungan Hidup dan dijadikan sebagai aturan wajib dalam uji tipe kendaraan bermotor, maka dibandingkan dengan bahan bakar Pertamax penggunaan bahan bakar LGV dengan mixer standard akan menaikkan emisi regulasi $\mathrm{CO}$ dan menurunkan emisi $\mathrm{HC}+\mathrm{NOx}$. Kenaikan emisi CO terutama terjadi pada siklus urban/perkotaan atau pada daya rendah, sedangkan pada siklus extra urban kondisi sebaliknya terjadi, dimana emisi CO bahan bakar LGV lebih rendah dibandingkan Pertamax.

b. Penggunaan LGV akan menurunan emisi gas rumah kaca (CO2), dengan pemakaian mixer standar terjadi penurunan masing-masing sebesar
9,2\% untuk siklus UN-ECE R-83 dengan start dingin dan $10,2 \%$ dengan start panas.

c. Tingginya emisi $\mathrm{CO}$ dan $\mathrm{HC}$ serta rendahnya emisi NOx untuk bahan bakar LGV menunjukkan terjadinya pembakaran yang tidak sempurna, terutama disebabkan oleh terlalu kayanya campuran udara-LGV (AFR) dibandingkan campuran udaraPertamax. Hal ini menunjukkan bahwa penggunaan mixer standard untuk bahan bakar CNG tidak otomatis sesuai untuk bahan bakar LGV.

d. Dari kesimpulan c di atas maka penggunaan mixer standard untuk CNG diperlukan optimasi pencampuran udara-LGV yang lebih baik untuk mendapatkan AFR yang sesuai dengan sifat-sifat LGV. Hal ini sejalan dengan hasil kajian awal menggunakan perengkat lunak fluent dengan dasar geometri mixer yang ada di pasar untuk kendaraan di bawah $3000 \mathrm{cc}$, dimana pada umumnya AFR yang didapat berada dalam campuran kaya. 


\section{DAFTAR PUSTAKA}

1. Prawoto, 2003, Emisi Gas Buang Kendaraan Bermotor dan Pengaruhnya Terhadap Lingkungan, Jurnal Termodinamika dan Fluida, No. 13.

2. Heywood, J.B., 1988, Internal Combustion Engine Fundamentals, McGraw-Hill Publishing Company.

3. Widodo, 2008,Optimasi Pencampuran Udara-Bahan bakar di dalam Mixer untuk Kendaraan Bermotor Berbahan Bakar Gas, Tesis Pascasarjana Magister Teknik Mesin, Universitas
Pancasila Jakarta.

4. UN-ECE 83-04 Regulations, 2000.

5. Bosch Robert, 2007, Automotive Hanbook. 7th edition. (C) Robert Bosch $\mathrm{GmbH}$. Germany.

6. Peraturan Menteri Negara Lingkungan Hidup, No. 04 Tahun 2009 Tentang: Ambang Batas Emisi Gas Buang Kendaraan Bermotor Tipe Baru, Jakarta, 2009.

7. Morita Yasuhiro, 2010, Current Status of NGV in Japan, The Japan Gas Association Natural Gas Vehicle Project Dept.Tokyo 